\title{
A unique approach to address concentrator photovoltaic cost and performance challenges (Presentation Video)
}

Scott Burroughs

Scott Burroughs, "A unique approach to address concentrator photovoltaic cost and performance challenges (Presentation Video)," Proc. SPIE 8821, High and Low Concentrator Systems for Solar Electric Applications VIII, 88210R (9 September 2013); doi: 10.1117/12.2050964

SPIE Event: SPIE Solar Energy + Technology, 2013, San Diego, California, United States 


\title{
A Unique Approach to Address Concentrator Photovoltaic Cost and Performance Challenges (Presentation Video)
}

Scott Burroughs, Semprius, Inc. (United States)

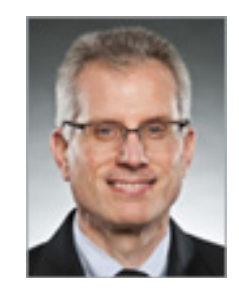

\begin{abstract}
Increasing the system performance, reducing costs, and demonstrating long term reliability are currently the three most important topics for CPV technologists to address. High volumes are necessary, but insufficient for reducing costs through economies of scale. What is required is a highly engineered solution to reduce the bill-of-materials cost while also increasing performance thus reducing the cost/performance ratio. The use of very small high efficiency multijunction solar cells enabled by massively parallel processing technology provides a pathway toward meeting the challenges of the CPV industry during the 2nd half of this decade.
\end{abstract}

View presentation video on SPIE's Digital Library: http://dx.doi.org/10.1117/12.2050964 